\title{
A birth cohort analysis of the smoking epidemic in West Germany
}

\author{
Hermann Brenner
}

\begin{abstract}
Study objective-The aim was to provide insights in the spread of the smoking epidemic and eventual progress against cigarette smoking in West Germany.

Design-This was a retrospective birth cohort analysis based on a cross sectional national survey.

Setting-The survey was conducted in 1987 by the Ministry of Youth, Family and Health in order to identify priorities for health policy and promotion. The target population were all residents of German nationality above the age of 14 years.
\end{abstract}

Study population-1721 men and women of the birth cohorts 1911-20, 1921-30, 1931$40,1941-50,1951-60$, and 1961-70 were included in this analysis $(65.7 \%$ overall response rate).

Measurements and main results-The participants were asked for their detailed life time history of cigarette smoking in a personal interview. This information was used to calculate and plot historical smoker prevalences by sex, level of school education, birth cohort, and calendar year after correcting for differential survival of smokers and non-smokers. In men, smoking prevalences increased slowly from birth cohort to birth cohort and reached a maximum of more than $70 \%$ in the $1941-50$ cohort in the early 1970s. While smoker prevalences were considerably lower in the two youngest birth cohorts among better educated men, no major changes were observed in men with lower educational status. The rise of the smoking epidemic in women seems to have levelled off only very recently.

Conclusions-In contrast to other countries with more powerful antismoking campaigns, no major progress in the fight against cigarette smoking has so far been made in West Germany. Major public health efforts are badly needed to limit the epidemic of smoking attributable diseases in this country.

f Epidemiol Community Health 1993; 47: 54-58

Cigarette smoking is well known to be the single most important preventable cause of death in many highly industrialised countries. ${ }^{1}$ Until the end of the 19th century, cigarette smoking was virtually unknown. ${ }^{2}$ However, in the 20th century the prevalence of cigarette smoking increased rapidly in an epidemic fashion and reached peak levels of $50 \%$ or more in the adult population of many countries. ${ }^{3-5}$ Since the landmark publication of the first Surgeon General's Report on Smoking and Health in $1964,{ }^{6}$ official recognition that cigarette smoking is a cause of cancer and other serious diseases led to the initiation of antismoking campaigns in a variety of countries. However, the intensity of these campaigns varied widely between nations: while massive efforts led to substantial reduction of smoking prevalence in some countries like the USA, ${ }^{1} 37$ little progress was made in other countries like the Federal Republic of Germany (FRG). ${ }^{2}$ Within countries, the level of school education has been consistently found to be an important predictor of changes in smoking behaviour: in those countries in which a decline in smoking prevalence was observed in recent years, the onset and the speed of the decline was much faster in subgroups of the population with higher educational levels. ${ }^{8-11}$

Changes in smoking prevalence are commonly monitored on the basis of repeated cross sectional surveys. This type of monitoring is usually limited to recent calendar periods, however, as reliable historical data on smoking prevalence are rarely available. On the other hand, in order to take full advantage of the lessons to be learnt from the smoking epidemic, monitoring over prolonged periods of time is most desirable. If cross sectional data are collected which include detailed data on the participants' lifetime smoking history, historical data may be reconstructed by appropriate epidemiological and demographic techniques. ${ }^{12}$ In this paper, detailed birth cohort analyses on smoking behaviour in Germany in the 20th century are presented, which are based on a national survey conducted in 1987 . Their medical, social, and political implications will be discussed.

\section{Methods}

POPULATION AND SAMPLE

This analysis is based on a national sample survey from West Germany which was conducted in 1987 by the Ministry of Youth, Family and Health in order to identify priorities for health policy and promotion. ${ }^{13}$ The target population were all residents of German nationality above the age of 14 years. A two stage sampling procedure was employed. In the first stage, a total of 2956 eligible households were randomly selected. In the second stage, one individual of the respective age group within each household was chosen at random.

Personal interviews were taken in a standardised manner at the place of residence by trained interviewers. Among the 2956 selected households, $166(5.6 \%)$ could not be contacted in spite 
of repeated attempts. One hundred and fifty six interviews $(5.3 \%)$ could not be carried out because of long term absence or severe sickness of the selected household member. Interviews were refused or not completed in 692 cases $(23.4 \%)$. With a total number of 1942 completed interviews, the overall response rate was $65.7 \%$.

In this analysis, only persons born between 1911 and 1970 were included. These persons were between 17 and 76 years old at the time of the interview. Analyses were carried out by sex, birth cohort (six 10 year cohorts from 1911-1920 to 1961-1970) and level of school education ( $\leqslant 9$ years and $>9$ years; these categories reflect standard education categories in Germany). Overall, there were 1800 men and women in the eligible age range. Seventy nine participants $(4.39 \%)$ were excluded due to missing information on their smoking history or level of school education. The numbers of participants within the categories of analysis are given in the table. No separate analyses are presented for the two categories with less than 25 participants due to the potentially large random error.

\section{LIFETIME SMOKING HISTORY}

Each participant was asked for his lifetime history of cigarette smoking (including, among others, calendar year of initiation and eventual cessation), which was used to reconstruct his smoking status for each calendar year between his birth and 1987, the year of the interview. People who had never smoked were classified as non-smokers for the entire period. Former smokers were classified as smokers for the period beginning with the year of initiation up to the year of cessation. Current smokers were classified as smokers for the period beginning with the year of initiation up to and including 1987, the year of the survey. Unsuccessful previous quitting attempts for which sufficiently detailed data were unavailable had to be neglected.

\section{CALCULATION OF SMOKING PREVALENCES}

For each birth cohort, the smoker prevalence was calculated by single calendar year up to 1987 . In order to obtain valid estimates of historical smoking prevalences the following corrections had to be made.

\section{(1) Correction for selective survival}

Cigarette smokers have higher mortality rates than non-smokers. ${ }^{14-21}$ As a result, uncorrected historical smoker prevalences derived from survivors of a given birth cohort tend to underestimate the true historical smoker prevalences. The corrections were made following a procedure proposed and described in detail by Harris. ${ }^{12}$ The

Number of participants by sex, birth cohort, and level of school education

\begin{tabular}{|c|c|c|c|c|c|c|c|c|}
\hline \multirow[b]{2}{*}{ Sex } & \multirow[b]{2}{*}{$\begin{array}{l}\text { School } \\
\text { education }\end{array}$} & \multicolumn{6}{|c|}{$\begin{array}{l}\text { Birth cohort } \\
\text { (Age at interview in 1987) }\end{array}$} & \multirow[b]{2}{*}{ Total } \\
\hline & & $\begin{array}{l}1911-20 \\
(67-76)\end{array}$ & $\begin{array}{l}1921-30 \\
(57-66)\end{array}$ & $\begin{array}{l}1931-40 \\
(47-56)\end{array}$ & $\begin{array}{l}1941-50 \\
(37-46)\end{array}$ & $\begin{array}{l}1951-60 \\
(27-36)\end{array}$ & $\begin{array}{l}1961-70 \\
(17-26)\end{array}$ & \\
\hline Male & $\begin{array}{l}\leqslant 9 \text { years } \\
>9 \text { years } \\
\text { Total }\end{array}$ & $\begin{array}{l}78 \\
19^{a} \\
97\end{array}$ & $\begin{array}{r}93 \\
52 \\
145\end{array}$ & $\begin{array}{r}80 \\
54 \\
134\end{array}$ & $\begin{array}{r}73 \\
74 \\
147\end{array}$ & $\begin{array}{r}60 \\
97 \\
157\end{array}$ & $\begin{array}{r}43 \\
83 \\
126\end{array}$ & $\begin{array}{l}427 \\
379 \\
806\end{array}$ \\
\hline Female & $\begin{array}{l}\leqslant 9 \text { years } \\
>9 \text { years } \\
\text { Total }\end{array}$ & $\begin{array}{c}111 \\
21^{a} \\
132\end{array}$ & $\begin{array}{r}116 \\
31 \\
147\end{array}$ & $\begin{array}{r}102 \\
40 \\
142\end{array}$ & $\begin{array}{r}77 \\
66 \\
143\end{array}$ & $\begin{array}{r}98 \\
121 \\
219\end{array}$ & $\begin{array}{r}44 \\
88 \\
132\end{array}$ & $\begin{array}{l}548 \\
367 \\
915\end{array}$ \\
\hline
\end{tabular}

${ }^{a}$ No separate analyses are presented for this cell because of the small number of persons procedure was modified for the application to the German population for which no large prospective cohort studies on total mortality of smokers and non-smokers are available. This was done by calculating hypothetical survival rates of smokers and non-smokers based on age specific mortality rates in the total population, age specific smoker prevalences, and estimates of relative death rates of smokers compared to non-smokers. The latter were estimated on the basis of large prospective cohort studies conducted in the white population of the United States as well as some defined European populations. ${ }^{14-21}$ A detailed description of the correction procedure which has a major impact only for the two oldest birth cohorts is given in the appendix.

\section{(2) Correction for selective response}

Uncorrected results of this survey are not necessarily fully representative of the target population as a result of the sampling scheme (overrepresentation of persons living in small households, see above) and the incomplete response. Sampling weights were therefore employed which were calculated in order to make the survey representative of the target population with regard to the distribution of basic sociodemographic variables in a complex poststratification procedure. ${ }^{13}$

\section{Results}

Figure 1 shows the birth cohort specific smoker prevalence for all men. It can be seen that smoking was already very common in the 1911-1920 birth cohort which reached a peak prevalence of more than $60 \%$ in the 1940 s and the early 1950 s. The peak prevalence continued to rise, however, in subsequent birth cohorts and reached a maximum of over $70 \%$ in the $1941-50$ birth cohort. Furthermore, the age when more than $60 \%$ of the cohort had taken up smoking advanced from 25-34 years in the 1911-20 cohort (calendar year 1945) to 17-26 years in the 1941-50 cohort (calendar year 1967). Only in the youngest two birth cohorts were considerably lower smoking prevalences observed.

Stratification by level of school education (figs 2 and 3 ) revealed the following educational differences. Overall, smoking prevalences were slightly lower in men with higher levels of school education than in less educated men in earlier birth cohorts. Beginning around 1970, these differences widened sharply: smoking prevalence fell from a peak level of more than $70 \%$ to about $40 \%$ in the higher educated men born in 1941-50 in contrast to only a minor decrease in the less educated men of the same birth cohort. This suggests successful smoking cessation in a large proportion of former smokers with higher educational levels. Furthermore, the reduction of the peak smoking prevalence in the youngest two birth cohorts was much more pronounced in the higher educated men. Nevertheless, the apparent re-increase of smoking prevalence in the youngest birth cohort with higher educational level is disquieting and requires careful further monitoring.

In contrast to the findings in men, smoking was very uncommon in women born prior to 1920 (fig 
4). However, smoking prevalences increased substantially from birth cohort to birth cohort and reached almost the same level as in men in the youngest two birth cohorts. Only in the youngest birth cohort does the increase in smoking prevalence seem to have levelled off. These latter patterns are essentially the same in women with lower (fig 5) and higher (fig 6) educational level. However, the analyses point to the leading role of the better educated women in the early phase of the smoking epidemic although these data have to

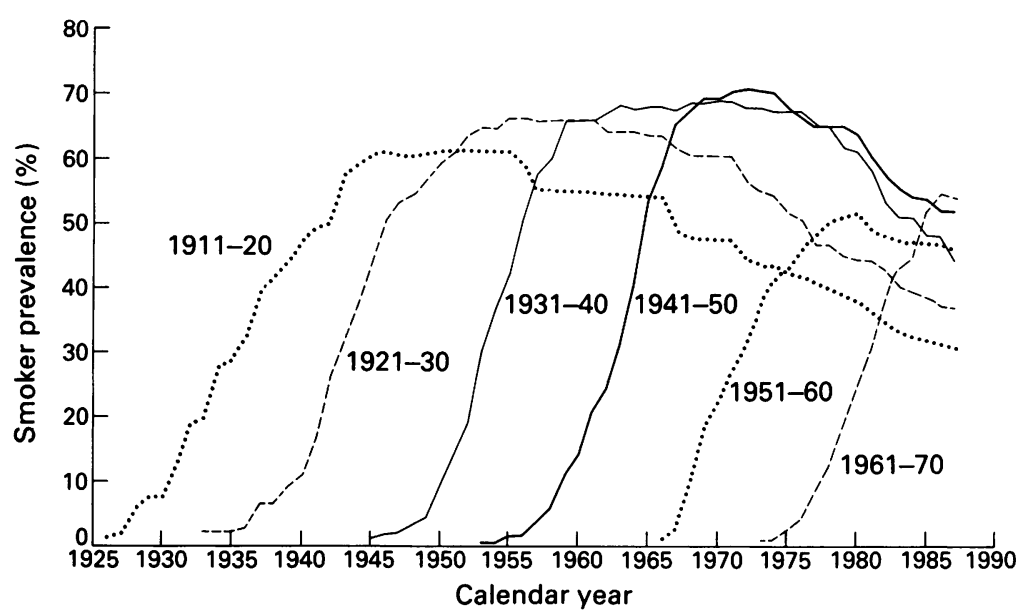

Figure 1 Smoker prevalence by birth cohort and calendar year in the total group of men

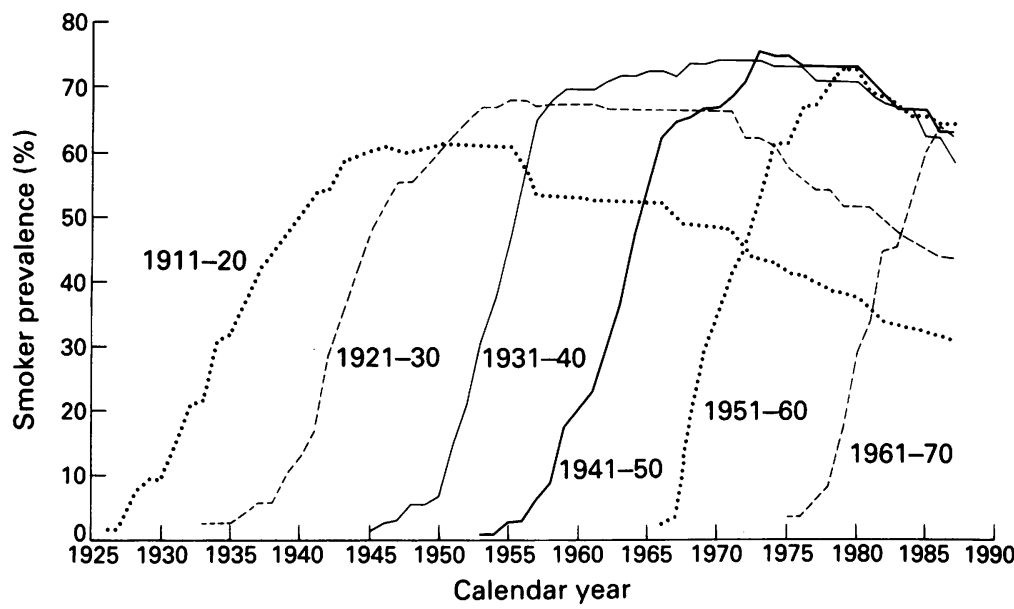

Figure 2 Smoker prevalence by birth cohort and calendar year in men with up to 9 years school education

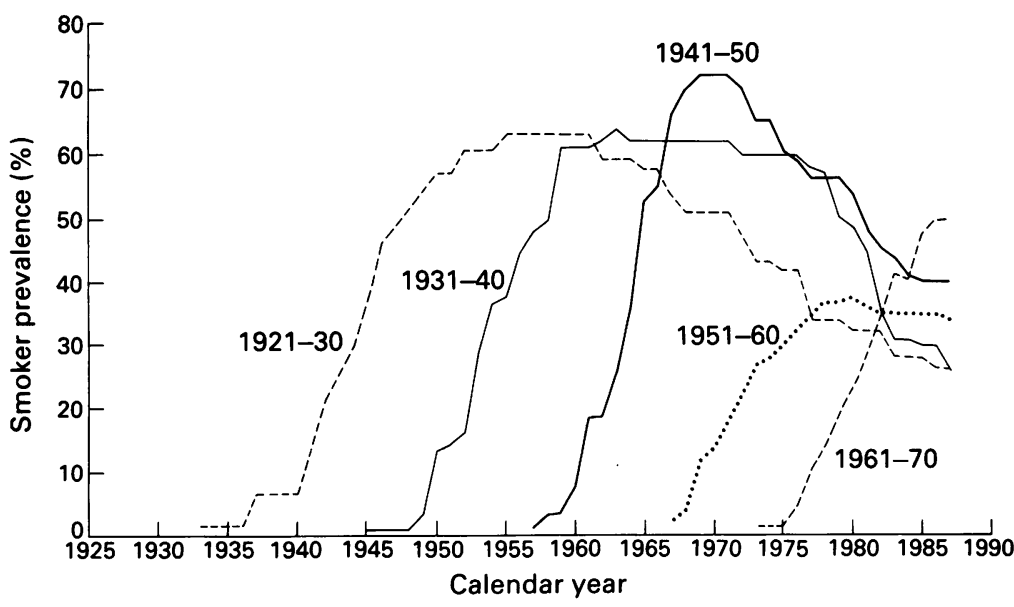

Figure 3 Smoker prevalence by birth cohort and calendar year in men with more than 9 years school education be interpreted with caution due to the small numbers of better educated women in the older cohorts (see table).

\section{Discussion}

In the interpretation of this study the following methodologic considerations have to be kept in mind.

First, the response rate of the survey was rather low (about $65 \%$ ). If respondents and nonrespondents differ by smoking history this may lead to distortions of the observed uncorrected smoker prevalences. In this analysis, there was some indirect evidence for such distortions as smoker prevalences were in most cases somewhat higher (differences usually $\leqslant 5 \%$ ) after correction for the sampling scheme and selective response through the application of appropriate weights. The potential bias due to selective response should, however, be small in the corrected smoker prevalences that are presented in this paper.

Second, the lifetime history of cigarette smoking given in the survey was not detailed enough to identify periods of contemporary smoking abstinence with sufficient accuracy. Current or former smokers should not contribute to the estimated smoking prevalences during such periods. As this was not possible with our data, the historical smoker prevalences may tend to be somewhat overestimated in our analysis. It is, however, questionable whether this overestimation is of relevant size: although $40.7 \%$ of current smokers indicated that they had tried to quit smoking at least once, these attempts usually only led to very short periods of abstinence. For example, the median time of abstinence at the last attempt was only two months. Other pertinent information on smoking habits, such as number and tar content of cigarettes smoked or type of inhalation, which could not be derived retrospectively in sufficient detail, also had to be ignored.

Third, while the total number of participants in the survey was rather high, some of the sex and education specific analyses are based on relatively small numbers and may be subject to major random error. This particularly applies to better educated men and women in the older birth cohorts, as well as less educated men and women in the youngest birth cohort. The results for these subgroups should therefore be interpreted cautiously. The numbers of participants born prior to 1910 were too small to derive meaningful smoker prevalences for older birth cohorts.

Despite these methodological limitations, the analyses reveal important information on the dynamics of the smoking epidemic in Germany that is less evident in traditional cross sectional analyses. The results discussed below are of particular public health relevance.

In contrast to other countries with much more powerful antismoking campaigns, ${ }^{12} 22$ the progress against the smoking epidemic has been very limited in the Federal Republic of Germany. Given the fact that the negative health effects and the enormous public health impact of cigarette smoking have been known for several decades, the ongoing rise of the smoking epidemic in women during this time period points to a tragic failure of health policy, health education, and health pro- 
motion that is likely to be responsible for a large burden of smoking related disease in the years to come. Only in the better educated men does there seem to be some evidence for a diminution in the smoking epidemic, although it appears to be cynical to talk of success, given that even in this group smoking prevalence still reaches peak levels of around $50 \%$. Rather, these results should be viewed as an indicator for the need for intensified efforts to reduce the smoking epidemic, especially in less educated population groups.

There is a large variety of public health interventions that might be initiated in the fight

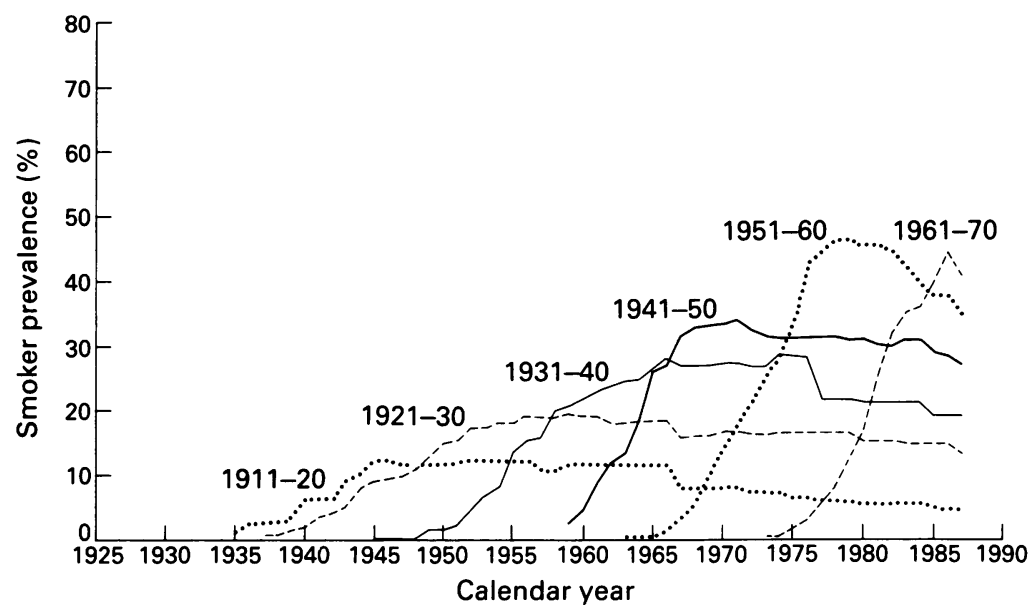

Figure 4 Smoker prevalence by birth cohort and calendar year in the total group of women

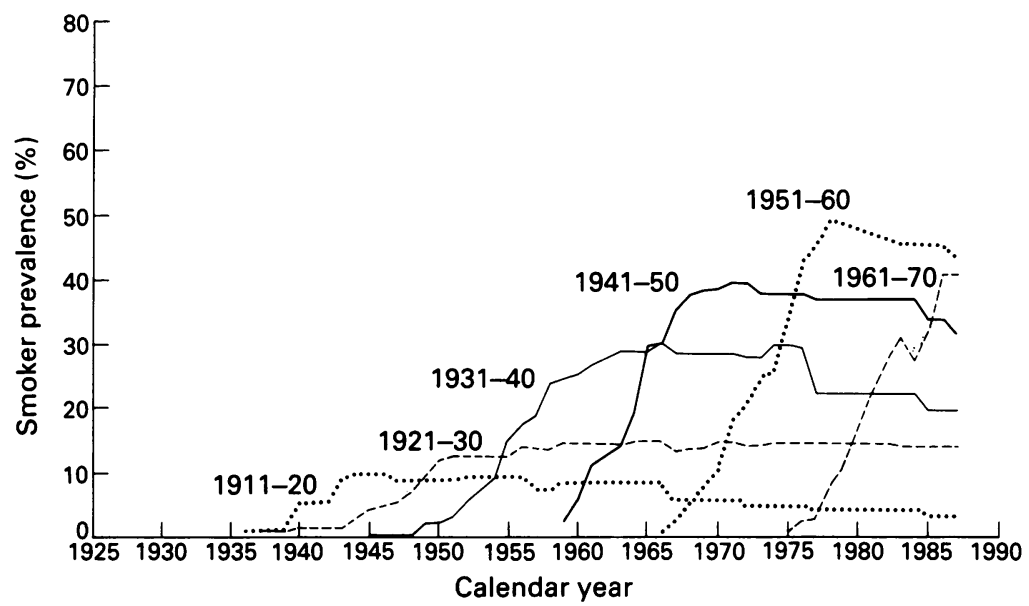

Figure 5 Smoker prevalence by birth cohort and calendar year in women with up to 9 years school education

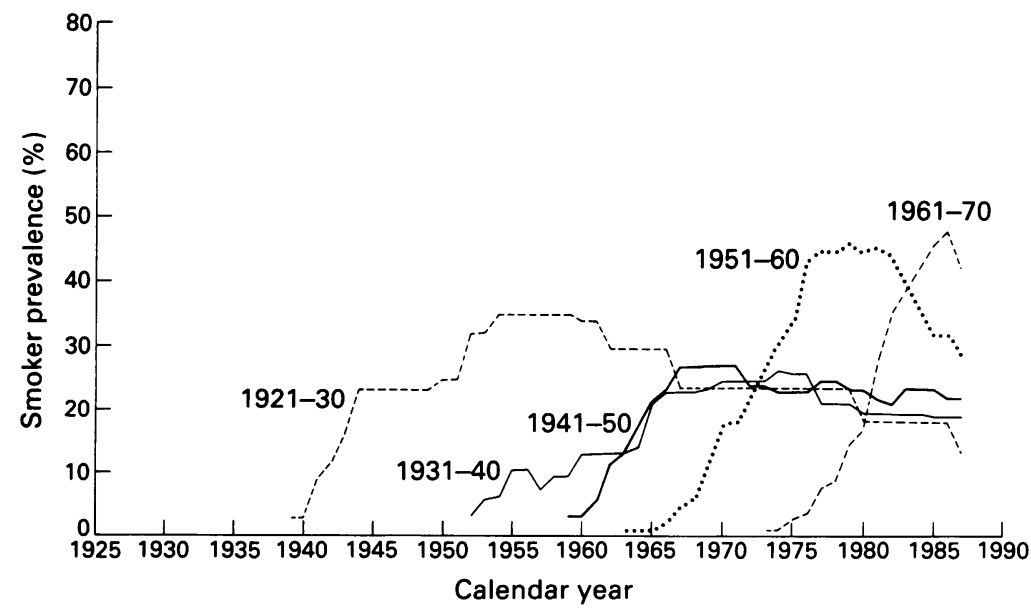

Figure 6 Smoker prevalence by birth cohort and calendar year in women with more than 9 years school education against the smoking epidemic. First, most smokers start smoking as teenagers. Comprehensive school health education, incorporating tobacco use prevention, should be provided in every school throughout the country. Such efforts might be supported by appropriate advertising restrictions ${ }^{23}$ and media campaigns. ${ }^{24}$ Second, smoking control programmes at the workplace should be promoted. ${ }^{25}$ These programmes should provide traditional offers, such as smoking cessation classes, self help materials, and one to one counselling. ${ }^{26}$ In addition, restrictive smoking policies should be implemented at the workplace, in public buildings and in transportation systems, as a measure of protection for non-smokers against passive smoking. These policies may also help many active smokers to quit. ${ }^{27}$

The price for the smoking epidemic is already very high. Even if we succeed to bring down the smoking epidemic in the near future it will take another few decades before the epidemic of some smoking related diseases, such as various forms of cancer, ${ }^{28}$ will level off. Health politicians in this country who still hesitate to take massive action against tobacco consumption should be aware of their coresponsibility for this ongoing epidemic.

The author gratefully acknowledges a helpful review of the manuscript by Dr Andreas Mielck.

\section{Appendix}

Following the notation introduced by Harris, ${ }^{12}$ let $\mathrm{p}_{\mathrm{tu}}$ denote the prevalence of cigarette smoking at age $t$ among respondents alive at age $u$, where $u \geqslant t$. Let $S_{\text {tu }}$ denote the proportion of smokers at age $t$ who survive to age $\mathrm{u}$, and let $\mathrm{N}_{\mathrm{tu}}$ denote the corresponding survival probability among those not smoking at age $t$. Then a corrected historical prevalence of cigarette smoking at age $t, p_{t t}$, can be derived from the prevalence of smoking in survivors to age $u, p_{t u}$, as

$$
\mathrm{p}_{\mathrm{tt}}=\frac{\mathrm{p}_{\mathrm{tu}} / \mathrm{S}_{\mathrm{tu}}}{\mathrm{p}_{\mathrm{tu}} / \mathrm{S}_{\mathrm{tu}}+\left(\mathbf{1}-\mathrm{p}_{\mathrm{tu}}\right) \mathrm{N}_{\mathrm{tu}}}
$$

In this study, $S_{t u}$ and $N_{t u}$ were estimated in the following way:

Let $T_{i(i+1)}$ denote the survival probability from age $i$ to age $i+1$ in the total population, let $\mathrm{q}_{i}$ denote the prevalence of smoking at age $i$, and let $R R_{i}$ denote the relative mortality of smokers compared to non-smokers at age $\mathrm{i}$. Then

$$
\mathrm{T}_{\mathrm{i}(\mathrm{i}+1)}=\left(1-\mathrm{q}_{\mathrm{i}}\right) \star \mathrm{N}_{\mathrm{i}(\mathrm{i}+1)}+\mathrm{q}_{\mathrm{i}} \star\left(1-\mathrm{RR}_{\mathrm{i}} \star\left(1-\mathrm{N}_{\mathrm{i}(\mathrm{i}+1)}\right)\right) .
$$

Inverting this equation leads to expressions for $\mathrm{N}_{\mathrm{i}(\mathrm{i}+1)}$ as well as $S_{i(i+1)}=R_{R_{i}}^{\star}\left(1-N_{i(i+1)}\right)$ as a function of $T_{i(i+1)}, q_{i}$ and $R R_{i}$. Furthermore, assuming constant smoking behaviour from age $t$ to age $u$,

$$
S_{t u}=I_{i=t}^{u-1} S_{i(i+1)} \text { and } N_{t u}=\underset{i}{u-1} N_{i(i+1)} \text {. }
$$

As mortality is rapidly increasing with age, the mortality rates in the 1980s, when the birth cohorts were more advanced in age, are most relevant for deriving corrected historical smoker prevalences. A life table of the FRG for the calendar period from 1980 to 1985 was therefore used to determine the $T_{t(t+1)}$. The corresponding $q_{i}$ values were directly estimated from the survey, assuming that changes in age specific smoking prevalence from the $1980-85$ period to 1987 are small. Finally, the following values were assigned to $R_{\mathrm{i}}: 1.7$ in men and 1.3 in women, for all $i>35$. These values are in the median range of results observed in large prospective studies on cigarette smoking and total mortality. ${ }^{14-21}$ No differences were assumed for total mortality in smokers 
and non-smokers before age 35 years as smoking related deaths are unlikely to occur at younger ages and any differences would only have a minimal impact given the very low mortality in this age group. Overall, the results of the correction procedure were not very sensitive to variation of the specific assumptions made and the correction procedure did not have a major impact on historical smoking prevalences of the cohorts born after 1930.

1 US Department of Health and Human Services. Reducin the health consequences of smoking. 25 years of progress. A the health consequences of smoking. 25 years of progress. A report of the Surgeon General. Rockville,

2 Stumpfe KD. Die Ausbreitung des Suchtstoffes Nikotin. In Deutsche Hauptstelle gegen Suchtgefahren. Jahrbuch 1989 Deutsche Hauptstelle gegen Suchtgefahren. Jahrbuch 1989

zur Frage der Suchtgefahren. Hamburg: Neuland, 1988. Pierce JP. International comparisons of trends in cigarette
smoking prevalence. Am $\mathcal{F}$ Public Health 1989; 79: 152-7. smoking prevalence. Am $\mathcal{F}$ Public Health 1989; 79: $152-7$.
LaVecchia C. Patterns of cigarette smoking and trends in ung cancer mortality in Italy. $f$ Epidemiol Community Health 1985; 39: 157-64.

5 Berrino F, Merletti F, Zubiri A, et al. A comparative study of moking, drinking and dietary habits in population samples in France, Italy, Spain and Switzerland. II. Tobacco smoking. Rev Epidemiol Sante Publique 1988; 36: 166-76.

6 US Public Health Service. Smoking and health. Report of the Advisory Committee to the Surgeon General of the Public Health Service. US Department of Health, Education and Welfare, Public Health Service, Center for Disease Control. PHS Publication No 1103, 1964.

7 Novotny TE, Fiore MC, Hatziandreu EJ, Giovina GA, Mills SL, Pierce JP. Trends in smoking by age and sex, United States 1974-1987: the implications for disease impact. Prev Med 1990; 19: 552-61.

8 Pierce JP, Fiore MC, Novotny TE, Hatziandreu EJ, Davis RM. Trends in cigarette smoking in the United States. Educational differences are increasing. $\mathcal{F} A M A 1989 ; 261$ 56-60.

9 Helmert U, Hermann B, Jöckel K-H, Greiser E, Madans J. Social class and risk factors for coronary heart disease in the Federal Republic of Germany. Results of the baseline survey of the German Cardiovascular Prevention Stud (GCP). F Epidemiol Community Health 1989; 43: 37-42.

10 Rosén M, Hanning M, Wall S. Changing smoking habits in Sweden: towards better health, but not for all. Int $f$ Epidemiol 1990; 19: 316-22.

11 Lundberg $O$, Rosén B, Rosén $M$. Who stopped smoking Results from a panel survey of living conditions in Sweden. Soc Sci Med 1991; 32: 619-22.
12 Harris JE. Cigarette smoking among successive birth cohorts of men and women in the United States durin 1900-80. ₹ Natl Cancer Inst 1983; 71: 473-9.

13 Bundeszentrale für Gesundheitliche Aufklärung Lebensalltag, gesundheitsrelevante Verhaltensweisen und persönliche Befindlichkeit. Köln, 1987.

14 ermmond EC, Horn D Smoking and death rates. Part I. Total mortality. F $A M A$ 1958; 166: 1159-72.

15 Kahn HA. The Dorn study of smoking and mortality among US Veterans: report on eight and one-half years of observation. Natl Cancer Inst Mongr 1966; 19: 1-125.

16 Hammond EC. Smoking in relation to death rates of on million men and women. Natl Cancer Inst Monogr 1966; 19 127-204

17 Doll R, Peto R. Mortality in relation to smoking: 20 years observations on male British doctors. $B M \mathcal{F} 1980 ; 280$ : 967-71.

18 Hawthorne VM, Fry JS Smoking and health: the association between smoking behaviour, total mortality and cardiorespiratory disease in west central Scotland. Epidemiol Community Health 1978; 32: 260-6.

19 Todd GF, Hunt BM, Lambert PM. Four cardiorespirator symptoms as predictors of mortality. $\mathcal{f}$ Epidemio

20 Doll R, Gray R, Hafner B, Peto R. Mortality in relation to smoking: 22 years' observations on female British doctors. BMF 1980; 280: 967-71.

21 Carstensen JM, Pershagen G, Eklund G. Mortality in relation to cigarette and pipe smoking: 16 years'observation of 25000 Swedish men. 7 Epidemiol Community Health 1987; 41: 166-72.

22 Christie D, Gordon I, Robinson K. Smoking in an industria population. An analysis by birth cohort. Med $\mathcal{F}$ Aust 1986; 145: $11-4$.

23 Warner KE Selling smoke: cigarette advertising and public health Washington DC. American Public Health Association, 1986 .

24 Pierce JP, Macaskill P, Hill D. Long-term effectiveness of mass media led antismoking campaigns in Australia. $A m \mathcal{F}$ Public Health 1990; 80: 565-9.

25 Fielding JE. Smoking control at the workplace. Annu Rev Public Health 1991; 12: 209-34.

26 Mielck A. Worksite smoking cessation programs: need in West Germany and recommendations for evaluation. So Praeventivmed 1990; 35: 125-8.

27 Brenner H, Mielck A. Smoking prohibition in the workplace and smoking cessation in the Federal Republic of Germany. Prev Med 1992; 21: 252-61.

28 Doll R, Peto R. The causes of cancer: quantitative estimates of avoidable risks of cancer in the United States today. $\mathscr{f}$ Natl Cancer Inst 1981; 66: 1191-308. 